\title{
Abdominal circumference should not be a required criterion for the diagnosis of metabolic syndrome
}

\author{
Kiyoshi Shibata $\cdot$ Sadao Suzuki $\cdot$ Juichi Sato $\cdot$ \\ Isao Ohsawa $\cdot$ Shinichi Goto $\cdot$ Masaru Hashiguchi $\cdot$ \\ Shinkan Tokudome
}

Received: 23 July 2009/Accepted: 25 December 2009/Published online: 4 February 2010

(C) The Japanese Society for Hygiene 2010

\begin{abstract}
Background Metabolic syndrome (MetS) is an established concept. However, it is characterized by a number of different definitions as well as different cut-off points (COPs) for waist circumference (WC) and different modes for incorporating WC into the diagnostic criteria.

Methods Abdominal ultrasonography was performed in 2,333 subjects who also underwent comprehensive medical examinations between April and July 2006. The odds ratios for the number of MetS components were calculated by taking central obesity status into account and considering concurrent fatty liver as an independent variable. We compared the areas under the receiver operating characteristic (ROC) curves for fatty liver and MetS using several MetS criteria.
\end{abstract}

K. Shibata $(\varangle) \cdot$ M. Hashiguchi

Kasugai City Medical Center, 1-1-7 Chuodai,

Kasugai, Aichi 487-0011, Japan

e-mail: s-kiyoshi@mvc.biglobe.ne.jp

K. Shibata $\cdot$ S. Suzuki $\cdot$ S. Tokudome

Department of Public Health, Nagoya City University

Graduate School of Medical Sciences, Nagoya, Japan

J. Sato

Department of General Medicine,

Nagoya University Hospital, Nagoya, Japan

I. Ohsawa

Department of Health Science,

Aichi Gakuin University, Nisshin, Aichi, Japan

S. Goto

Department of Medical Laboratory,

Kasugai Municipal Hospital, Kasugai, Japan

S. Tokudome

National Institute of Health and Nutrition, Tokyo, Japan
Results Regardless of the WC criterion selected, we observed a strong linear trend for an association (trend $P<0.0001$ ) between MetS and the number of components. The odds ratio (OR) of subjects without central obesity but with all three MetS components was 9.69 (95\% confidence interval 3.11-30.2) in men and 55.3 (6.34-483) in women. The COP for the largest area under the curve in men and women was $\geq 82 \mathrm{~cm}$ (OR 0.701) and $\geq 77 \mathrm{~cm}$ (OR 0.699), respectively, when WC was considered as a component. When WC distribution is taken into consideration, practical and appropriate COPs should be $\geq 85 \mathrm{~cm}$ for men and $\geq 80 \mathrm{~cm}$ for women.

Conclusion We suggest that a WC of $\geq 85 \mathrm{~cm}$ for men and $\geq 80 \mathrm{~cm}$ for women would be optimal COPs for the central obesity criteria in the Japanese population. In addition, central obesity should be incorporated as a component of MetS rather than an essential requirement for the diagnosis of MetS.

Keywords Central obesity - Diagnostic criteria · Metabolic syndrome $\cdot$ ROC curve

\section{Introduction}

The prevention of metabolic syndrome (MetS), for which visceral fat accumulation and insulin resistance are considered upstream factors, has recently attracted the attention of the medical world as a useful approach to protect against lifestyle-related diseases typified by arteriosclerotic diseases [1-8]. Visceral fat accumulates for many reasons, including hyperalimentation and inadequate exercise, among others, and causes the abnormal functioning of fat cells and excessive secretion of hormones that are involved in various pathological conditions $[9,10]$. Excessive 
secretion of these hormones is thought to act in combination with other factors to cause arteriosclerotic and other serious diseases, such as renal failure, blindness, lower limb amputation, cerebral apoplexy, cardiac arrest, and cerebrovascular diseases. The progression of conditions, from obesity into serious diseases, is sometimes referred as the metabolic domino effect $[11,12]$, and includes fatty liver disease.

Diagnostic criteria for MetS have been published by the World Health Organization [13], American National Cholesterol Education Programs, Adult Treatment Panel III (NCEP-ATP III) [14], and International Diabetes Federation (IDF) [15] for Asian countries, including Japan [16]. In Japan, the Examination Committee for Criteria of MetS introduced diagnostic criteria for Japanese metabolic syndrome (JMetS) [16], which are similar to the ones defined by IDF. The criteria essentially include central obesity and several other components, such as hypertension, hyperglycemia, and abnormal lipid metabolism. In Japan, the most prominent difference between the IDF and Examination Committee criteria for evaluating central obesity is in the cut-off point (COP) for waist circumference (WC), especially that for women: in all countries of the world, with the exception of Japan, the COP for WC is larger for men than that for women.

The relative newness of the MetS concept necessitates that the diagnostic criteria be updated as and when needed. The association between the diagnosis of MetS and downstream diseases in the metabolic domino needs to be addressed in prospective studies. In the study reported here, we applied several criteria to examine the association between metabolic status and concurrent fatty liver, which we used as a specific example of a disease in the metabolic domino. Our aim was to identify preliminary criteria and COPs for WC that can be used in diagnosing MetS.

\section{Subjects and methods}

Height, weight, and WC were measured, and abdominal ultrasonography was performed in 2,333 subjects $(1,195$ men and 1,138 women) of 2,428 subjects aged 4079 years. These subjects underwent comprehensive medical examinations at the Kasugai City Medical Center during a 3-month period between April and July 2006. Patients receiving drug treatment(s) for liver diseases, hypertension, diabetes mellitus, or hyperlipidemia were excluded from the study. Height and weight were measured using an automatic scale (Tanita BF-220). The WC was measured in standing subjects with a tape measure placed horizontally at the level of the navel while the subject was gently exhaling. If the abdomen was protuberant and the navel was deviated downwards, the tape measure was placed at the midpoint level between the lower intercostal border and the anterior superior iliac spine.

Fatty liver was diagnosed after discussion with medical technologists (including ultrasound technicians), radiology technologists, and physicians and by taking fatty liver scores (as shown in Table 1) obtained at Kasugai City Medical Center into consideration. These scores were based on previous studies [17-20].

Blood pressure was measured on the right arm using a mercury sphygmomanometer; the subject was in a lying position and had rested for at least 5 min prior to the measurement. Venous blood samples were collected in the morning from subjects after a fasting period of $12 \mathrm{~h}$. Triglyceride (TG) and serum high-density lipoprotein cholesterol (HDL-C) were measured by the direct enzymatic method, and fasting plasma glucose (FPG) was measured by the glucose oxidase method. Their concentrations were measured using an automated analyzer (model 7170S; Hitachi, Japan).

Current JMetS criteria require a central obesity (visceral adipose tissue area $\geq 100 \mathrm{~cm}^{2}$ or $\mathrm{WC} \geq 85 \mathrm{~cm}$ for men and $\geq 90 \mathrm{~cm}$ for women) and two or more of the following three components: (1) high blood pressure, based on a systolic blood pressure $\geq 130 \mathrm{mmHg}$ and/or diastolic blood pressure $\geq 85 \mathrm{mmHg}$; (2) hyperglycemia, based on FPG $\geq 110 \mathrm{mg} / \mathrm{dl}$; (3) abnormal lipid metabolism, based on TG $\geq 150 \mathrm{mg} / \mathrm{dl}$ and/or HDL-C $<40 \mathrm{mg} / \mathrm{dl}$ [16]. The Examination Committee for Criteria of MetS in Japan also defined a "risk group for MetS" (yobi-gun) consisting of people who have central obesity and one of the three components listed above (high blood pressure, hyperglycemia, or abnormal lipid metabolism). In our study, as in most epidemiological studies, only WC was considered in our evaluation of central obesity; the visceral adipose tissue area was not assessed.

Our primary aim was to identify and propose new MetS criteria based on our results. Our suggested criteria (our criterion 1) considers central obesity not to be an essential requirement for MetS but as only one of the components of MetS. Accordingly, we defined our patients as having MetS when they demonstrated three or more components of

Table 1 Fatty liver score

\begin{tabular}{ll}
\hline Condition & Points \\
\hline Bright echo pattern & 0 or 1 \\
Hepatorenal or hepatosplenic contrast & 0 or 1 or 2 \\
Unclear vessels & 0 or 1 \\
Deep attenuation & 0 or 1 or 2 \\
Fatty bandless sign & 0 or 1 \\
Liver swelling & 0 or 1 \\
\hline
\end{tabular}

A total score of $\geq 3$ points is considered to indicate fatty liver 
MetS, regardless of their central obesity status. Similarly, the risk group for MetS consisted of those individuals who demonstrated two components.

Taking the number of MetS components listed above in consideration, we first calculated the odds ratios of fatty liver according to central obesity status in men and women by logistic regression. We then constructed receiver operating characteristic (ROC) curves to assess the detecting power of MetS criteria for concurrent fatty liver and calculated the areas under the curve (AUC) for diagnostic criteria. These procedures were repeated using the IDF COP for WC in the Japanese population, i.e., $\geq 90 \mathrm{~cm}$ for men and $\geq 80 \mathrm{~cm}$ for women (our criterion 2). We also calculated the COP for the largest AUC and suggested an optimal COP for men and women based on the study results. Statistical analyses were performed using the SAS system for Windows (release 9.1.3; SAS Institute, Cary, $\mathrm{NC}$ ), and the AUC value was obtained to refer to the c statistic in PROC LOGISTIC output. All statistical tests were two-sided, and a $P$ value $<0.05$ was considered to be significant. The study was approved by the ethics committee of Nagoya City University.

\section{Results}

Table 2 shows the number of subjects diagnosed with MetS according to the JMetS criteria and our newly proposed criteria, respectively. This diagnosis was based on the number of MetS components, other than central obesity, calculated by WC status in both men and women. Only $8.4 \%$ of the women satisfied the central obesity criterion of JMetS, whereas $26.7 \%$ men satisfied the criterion. When the COP for central obesity was changed to $\geq 80 \mathrm{~cm}$, $36.6 \%$ of women satisfied the criterion. Among the 13 men and six women who were newly diagnosed with MetS based on our criteria using the same WC COP, seven men $(53.8 \%)$ and five women $(83.3 \%)$ had fatty liver. The

Table 2 Criteria of metabolic syndrome and number of subjects

\begin{tabular}{|c|c|c|c|c|c|c|}
\hline $\begin{array}{l}\text { Number of } \\
\text { components }{ }^{\mathrm{a}}\end{array}$ & $\begin{array}{l}\text { Criteria } \\
\text { of JMetS }\end{array}$ & $\begin{array}{l}\text { Our } \\
\text { criteria }\end{array}$ & $\begin{array}{l}\text { Number of patients } \\
\text { diagnosed with MetS }\end{array}$ & $\begin{array}{l}\text { Criteria } \\
\text { of JMetS }\end{array}$ & $\begin{array}{l}\text { Our } \\
\text { criteria }\end{array}$ & $\begin{array}{l}\text { Number of patients } \\
\text { diagnosed with MetS }\end{array}$ \\
\hline \multicolumn{7}{|l|}{ Men } \\
\hline & \multicolumn{3}{|c|}{ Waist circumference $<85 \mathrm{~cm}$} & \multicolumn{3}{|c|}{ Waist circumference $\geq 85 \mathrm{~cm}$} \\
\hline 0 & Normal & Normal & $391(32.7 \%)$ & Normal & Normal & $93(7.8 \%)$ \\
\hline 1 & Normal & Normal & $357(29.9 \%)$ & Risk MetS & Risk MetS & $152(12.7 \%)$ \\
\hline 2 & Normal & Risk MetS & $115(9.6 \%)$ & MetS & MetS & $61(5.1 \%)$ \\
\hline 3 & Normal & MetS & $13(1.1 \%)$ & MetS & MetS & $13(1.1 \%)$ \\
\hline \multirow[t]{2}{*}{ Total } & & & $876(73.3 \%)$ & & & $319(26.7 \%)$ \\
\hline & \multicolumn{3}{|c|}{ Waist circumference $<90 \mathrm{~cm}$} & \multicolumn{3}{|c|}{ Waist circumference $\geq 90 \mathrm{~cm}$} \\
\hline 0 & - & Normal & $453(37.9 \%)$ & - & Normal & $31(2.6 \%)$ \\
\hline 1 & - & Normal & $457(38.2 \%)$ & - & Risk MetS & $52(4.4 \%)$ \\
\hline 2 & - & Risk MetS & $151(12.6 \%)$ & - & MetS & $25(2.1 \%)$ \\
\hline 3 & - & MetS & $20(1.7 \%)$ & - & MetS & $6(0.5 \%)$ \\
\hline Total & & & $1,081(90.5 \%)$ & & & $114(9.5 \%)$ \\
\hline \multicolumn{7}{|l|}{ Women } \\
\hline & \multicolumn{3}{|c|}{ Waist circumference $<90 \mathrm{~cm}$} & \multicolumn{3}{|c|}{ Waist circumference $\geq 90 \mathrm{~cm}$} \\
\hline 0 & Normal & Normal & $603(53.0 \%)$ & Normal & Normal & $28(2.5 \%)$ \\
\hline 1 & Normal & Normal & $357(31.4 \%)$ & Risk MetS & Risk MetS & $45(4.0 \%)$ \\
\hline 2 & Normal & Risk MetS & $76(6.7 \%)$ & MetS & MetS & $18(1.6 \%)$ \\
\hline 3 & Normal & MetS & $6(0.5 \%)$ & MetS & MetS & $5(0.4 \%)$ \\
\hline \multirow[t]{2}{*}{ Total } & & & $1,042(91.6 \%)$ & & & $96(8.4 \%)$ \\
\hline & \multicolumn{3}{|c|}{ Waist circumference $<80 \mathrm{~cm}$} & \multicolumn{3}{|c|}{ Waist circumference $\geq 80 \mathrm{~cm}$} \\
\hline 0 & - & Normal & $458(40.2 \%)$ & - & Normal & $173(15.2 \%)$ \\
\hline 1 & - & Normal & $211(18.5 \%)$ & - & Risk MetS & $191(16.8 \%)$ \\
\hline 2 & - & Risk MetS & $49(4.3 \%)$ & - & MetS & $45(4.0 \%)$ \\
\hline 3 & - & MetS & $4(0.4 \%)$ & - & MetS & $7(0.6 \%)$ \\
\hline Total & & & $722(63.4 \%)$ & & & $416(36.6 \%)$ \\
\hline
\end{tabular}

JMetS Japanese metabolic syndrome, Risk MetS individuals with central obesity and one of three components (high blood pressure, hyperglycemia, or abnormal lipid metabolism), as defined by the Examination Committee for Criteria of MetS in Japan, MetS individuals with MetS

${ }^{\text {a }}$ Number of the components of MetS other than abdominal obesity 
prevalence of fatty liver was much higher than the total prevalence of fatty liver in men and women, i.e., 27.1 and $16.5 \%$, respectively.

Table 3 shows the characteristics of the subjects diagnosed with MetS based on the application of several criteria. The prevalence of MetS using the JMetS criteria was $6.2 \%$ in men and $2.0 \%$ in women; based on our criteria using the JMetS COP for central obesity, MetS prevalence was 7.3 and $2.5 \%$, respectively. When we applied the criterion for $\geq 80 \mathrm{~cm}$ COP for central obesity in women using our criteria, the prevalence of fatty liver increased to $4.9 \%$. Similarly, the application of the COP increased the prevalence among the MetS risk group to $21.1 \%$, which was close to that observed in men according to our criteria which include the $\geq 85 \mathrm{~cm}$ COP for central obesity. Since central obesity is an essential criterion for determining JMetS or the JMetS risk group, the subjects in these categories are much more obese than those falling in the normal category. The difference in WC and BMI between subjects in the MetS group and the normal group was $12.1 \mathrm{~cm}$ and $3.5 \mathrm{~kg} / \mathrm{m}^{2}$, respectively, in men and $17.6 \mathrm{~cm}$ and $5.7 \mathrm{~kg} / \mathrm{m}^{2}$ in women. When our criteria were used, these differences decreased to $10.4 \mathrm{~cm}$ and $3.0 \mathrm{~kg} / \mathrm{m}^{2}$, respectively, in men and $14.5 \mathrm{~cm}$ and $5.0 \mathrm{~kg} / \mathrm{m}^{2}$ in women.

Table 3 Characteristics of the subjects by MetS status

\begin{tabular}{|c|c|c|c|c|c|c|}
\hline \multirow[t]{2}{*}{ Characteristics } & \multicolumn{3}{|l|}{ Men } & \multicolumn{3}{|l|}{ Women } \\
\hline & Normal & Risk MetS & MetS & Normal & Risk MetS & MetS \\
\hline Criteria of JMetS (cut-off of WC) & $(85 \mathrm{~cm})$ & & & $(90 \mathrm{~cm})$ & & \\
\hline Number (row\%) & $969(81.1 \%)$ & $152(12.7 \%)$ & $74(6.2 \%)$ & $1,070(94.0 \%)$ & $45(4.0 \%)$ & $23(2.0 \%)$ \\
\hline Fatty liver prevalence $(\%)$ & $20.6 \%$ & $46.1 \%$ & $73.0 \%$ & $14.5 \%$ & $40.0 \%$ & $65.2 \%$ \\
\hline Age (years) & $63.0 \pm 8.8$ & $63.3 \pm 8.4$ & $63.4 \pm 7.9$ & $61.6 \pm 8.0$ & $65.8 \pm 8.1$ & $64.4 \pm 6.7$ \\
\hline BMI $\left(\mathrm{kg} / \mathrm{m}^{2}\right)$ & $22.3 \pm 2.4$ & $25.8 \pm 2.4$ & $25.8 \pm 2.5$ & $21.7 \pm 2.6$ & $27.2 \pm 3.4$ & $27.4 \pm 3.1$ \\
\hline $\mathrm{WC}(\mathrm{cm})$ & $77.8 \pm 6.4$ & $89.6 \pm 5.3$ & $89.9 \pm 4.9$ & $76.5 \pm 7.5$ & $95.0 \pm 5.1$ & $94.1 \pm 3.7$ \\
\hline Systolic blood pressure (mmHg) & $122.6 \pm 15.1$ & $126.5 \pm 16.0$ & $136.2 \pm 12.4$ & $122.2 \pm 17.0$ & $132.0 \pm 13.8$ & $142.3 \pm 14.7$ \\
\hline Diastolic blood pressure $(\mathrm{mmHg})$ & $71.9 \pm 8.6$ & $75.0 \pm 8.9$ & $79.9 \pm 8.2$ & $70.5 \pm 9.3$ & $74.6 \pm 8.3$ & $79.3 \pm 7.0$ \\
\hline Triglycerides (mg/dl) & $114.3 \pm 70.8$ & $142.7 \pm 71.6$ & $196.2 \pm 150.0$ & $97.5 \pm 49.8$ & $120.7 \pm 52.7$ & $204.5 \pm 101.1$ \\
\hline HDL-cholesterol (mg/dl) & $62.1 \pm 16.4$ & $53.3 \pm 12.6$ & $51.9 \pm 14.8$ & $72.2 \pm 17.1$ & $64.7 \pm 14.3$ & $54.1 \pm 13.6$ \\
\hline Fasting glucose (mg/dl) & $96.0 \pm 17.2$ & $100.0 \pm 18.1$ & $122.9 \pm 48.1$ & $92.4 \pm 15.8$ & $95.1 \pm 13.5$ & $117.3 \pm 30.9$ \\
\hline Our criteria 1 (cut-off of WC) & $(85 \mathrm{~cm})$ & & & $(90 \mathrm{~cm})$ & & \\
\hline Number (row\%) & $841(70.4 \%)$ & $267(22.3 \%)$ & $87(7.3 \%)$ & $988(86.8 \%)$ & $121(10.6 \%)$ & $29(2.5 \%)$ \\
\hline Fatty liver prevalence $(\%)$ & $17.6 \%$ & $43.1 \%$ & $70.1 \%$ & $12.7 \%$ & $35.5 \%$ & $69.0 \%$ \\
\hline Age (years) & $62.7 \pm 8.9$ & $63.9 \pm 8.1$ & $64.2 \pm 8.0$ & $61.3 \pm 8.0$ & $64.7 \pm 7.9$ & $64.8 \pm 6.8$ \\
\hline BMI $\left(\mathrm{kg} / \mathrm{m}^{2}\right)$ & $22.2 \pm 2.5$ & $24.5 \pm 2.7$ & $25.2 \pm 2.6$ & $21.7 \pm 2.6$ & $24.0 \pm 3.7$ & $26.7 \pm 3.2$ \\
\hline $\mathrm{WC}(\mathrm{cm})$ & $77.6 \pm 6.6$ & $84.9 \pm 7.2$ & $88.0 \pm 6.7$ & $76.4 \pm 7.6$ & $84.3 \pm 10.1$ & $90.9 \pm 7.6$ \\
\hline Systolic blood pressure (mmHg) & $120.5 \pm 14.1$ & $130.8 \pm 15.9$ & $137.1 \pm 11.9$ & $120.7 \pm 16.3$ & $137.2 \pm 14.0$ & $143.9 \pm 14.4$ \\
\hline Diastolic blood pressure (mmHg) & $71.0 \pm 8.3$ & $76.1 \pm 9.0$ & $79.4 \pm 8.0$ & $69.9 \pm 9.1$ & $76.8 \pm 8.7$ & $79.9 \pm 7.5$ \\
\hline Triglycerides (mg/dl) & $103.8 \pm 50.2$ & $159.2 \pm 103.1$ & $197.4 \pm 140.9$ & $91.2 \pm 40.2$ & $152.1 \pm 76.4$ & $207.7 \pm 92.4$ \\
\hline HDL-cholesterol (mg/dl) & $63.2 \pm 16.0$ & $54.4 \pm 15.0$ & $51.3 \pm 14.8$ & $73.0 \pm 16.8$ & $63.3 \pm 16.7$ & $55.2 \pm 14.0$ \\
\hline Fasting glucose (mg/dl) & $93.2 \pm 12.2$ & $105.3 \pm 24.5$ & $124.5 \pm 45.0$ & $91.2 \pm 13.9$ & $100.3 \pm 21.6$ & $121.9 \pm 33.2$ \\
\hline Our criteria 2 (cut-off of WC) & $(90 \mathrm{~cm})$ & & & $(80 \mathrm{~cm})$ & & \\
\hline Number (row\%) & $941(78.7 \%)$ & $203(17.0 \%)$ & $51(4.3 \%)$ & $842(74.0 \%)$ & $240(21.1 \%)$ & $56(4.9 \%)$ \\
\hline Fatty liver prevalence $(\%)$ & $19.6 \%$ & $50.2 \%$ & $74.5 \%$ & $10.3 \%$ & $27.9 \%$ & $60.7 \%$ \\
\hline Age (years) & $62.8 \pm 8.8$ & $64.0 \pm 8.2$ & $63.9 \pm 7.9$ & $60.6 \pm 8.0$ & $64.9 \pm 7.2$ & $64.6 \pm 7.7$ \\
\hline BMI $\left(\mathrm{kg} / \mathrm{m}^{2}\right)$ & $22.5 \pm 2.5$ & $24.3 \pm 3.0$ & $25.6 \pm 3.3$ & $21.3 \pm 2.5$ & $23.9 \pm 3.1$ & $25.4 \pm 2.9$ \\
\hline $\mathrm{WC}(\mathrm{cm})$ & $78.6 \pm 6.9$ & $84.3 \pm 8.2$ & $88.8 \pm 8.6$ & $75.0 \pm 7.4$ & $84.3 \pm 7.4$ & $87.8 \pm 6.6$ \\
\hline Systolic blood pressure $(\mathrm{mmHg})$ & $121.2 \pm 14.4$ & $133.4 \pm 15.5$ & $138.2 \pm 11.5$ & $118.1 \pm 14.9$ & $135.5 \pm 15.2$ & $143.1 \pm 14.8$ \\
\hline Diastolic blood pressure (mmHg) & $71.5 \pm 8.4$ & $76.9 \pm 9.1$ & $80.2 \pm 7.9$ & $68.8 \pm 8.6$ & $76.1 \pm 8.8$ & $79.8 \pm 8.0$ \\
\hline Triglycerides $(\mathrm{mg} / \mathrm{dl})$ & $107.6 \pm 53.0$ & $172.0 \pm 112.7$ & $211.2 \pm 172.3$ & $87.0 \pm 36.5$ & $126.3 \pm 56.4$ & $195.5 \pm 102.1$ \\
\hline HDL-cholesterol (mg/dl) & $62.2 \pm 15.9$ & $54.7 \pm 16.1$ & $50.1 \pm 14.9$ & $74.6 \pm 16.6$ & $64.2 \pm 15.7$ & $56.4 \pm 13.3$ \\
\hline Fasting glucose (mg/dl) & $93.9 \pm 13.4$ & $109.7 \pm 28.2$ & $131.1 \pm 49.9$ & $90.8 \pm 14.4$ & $95.4 \pm 14.7$ & $115.5 \pm 30.7$ \\
\hline
\end{tabular}

Data are given as the mean \pm standard deviation (SD)

$W C$ Waist circumference, $B M I$ body mass index, $H D L$ high-density lipoprotein 
When the COP of $\geq 80 \mathrm{~cm}$ was applied, the differences decreased to $12.8 \mathrm{~cm}$ and $4.1 \mathrm{~kg} / \mathrm{m}^{2}$, respectively.

Table 4 shows the odds ratios and 95\% confidence interval (CI) for fatty liver according to the number of MetS components other than central obesity by WC status. Regardless of sex and the WC COP selected, a strong linear trend was observed for the association (trend $P<0.0001$ ) with the number of components. The odds ratio for subjects without central obesity and with all three components of MetS was 9.69 (95\% CI 3.1130.2) in men and 55.3 (6.34483 ) in women. Using the $\geq 90$ and $\geq 80 \mathrm{~cm}$ COP criterion for central obesity in men and women, respectively, the odds ratio was $55.3(6.34-483)$ and 62.4 (6.23-626). These point estimates of odds ratios were higher than those of MetS subjects with two risk factors other than obesity among women, and even among men, they were higher than those of the risk group for MetS who satisfied the central obesity criterion.

Figure 1 shows the ROC curves for the diagnosis of fatty liver according to MetS status by the JMetS criteria and by our criteria. The AUC for the JMetS criteria and our criteria 1 and 2 in men was $0.638,0.681$, and 0.655 , respectively. In women, the AUC for our criteria using $\geq 90$ and $\geq 80 \mathrm{~cm}$ COPs for central obesity were 0.625 and 0.681 , respectively, whereas that for the JMetS criteria was only 0.570 . Based on the findings of our study, the largest AUC was recorded using our criterion 1 $(\geq 85 \mathrm{~cm})$ in men and our criteria 2 in women $(\geq 80 \mathrm{~cm})$. The shapes of the ROC curves of our criterion 2 for men and our criterion 1 for women were very similar, with the coordinates (false positive rate, true positive rate) for MetS and the risk group for MetS being $(0.030,0.188)$ and $(0.204,0.543)$, respectively, for men and $(0.023$, $0.181)$ and $(0.205,0.537)$, respectively for women. In addition, when WC was considered as a component, the COP for the largest AUC among men and women was $\geq 82 \mathrm{~cm}$ (0.701) and $\geq 77 \mathrm{~cm}$ (0.699), respectively. We therefore conclude that it would be both practical and appropriate to take WC into consideration, with WC COPs of $\geq 85 \mathrm{~cm}$ for men and $\geq 80 \mathrm{~cm}$ for women. In our study population, $26.7 \%$ of the men and $36.6 \%$ the women satisfied the criteria.

Table 4 Odds ratio and 95\% confidence interval for fatty liver according to the number of the components of MetS other than obesity by waist circumstance status

\begin{tabular}{|c|c|c|c|c|}
\hline Number of the components ${ }^{\mathrm{a}}$ & Odds ratio & $95 \%$ confidence interval & Odds ratio & $95 \%$ confidence interval \\
\hline \multicolumn{5}{|l|}{ Men } \\
\hline & \multicolumn{2}{|c|}{ Waist circumference $<85 \mathrm{~cm}$} & \multicolumn{2}{|c|}{ Waist circumference $\geq 85 \mathrm{~cm}$} \\
\hline 0 & 1.00 & Reference & 5.49 & $3.25-9.27$ \\
\hline 1 & 1.99 & $1.32-3.01$ & 7.09 & $4.51-11.1$ \\
\hline 2 & 5.34 & $3.26-8.74$ & 18.4 & $9.78-34.4$ \\
\hline 3 & 9.69 & $3.11-30.2$ & 99.7 & $12.6-786$ \\
\hline \multirow[t]{2}{*}{$P$ for trend } & $<0.0001$ & & $<0.0001$ & \\
\hline & \multicolumn{2}{|c|}{ Waist circumference $<90 \mathrm{~cm}$} & \multicolumn{2}{|c|}{ Waist circumference $\geq 90 \mathrm{~cm}$} \\
\hline 0 & 1.00 & Reference & 7.66 & $3.59-16.32$ \\
\hline 1 & 1.88 & $1.33-2.66$ & 11.91 & $6.34-22.39$ \\
\hline 2 & 5.17 & $3.40-7.85$ & 19.96 & $7.67-51.93$ \\
\hline 3 & 14.71 & $5.45-39.72$ & 31.53 & $3.62-274.34$ \\
\hline$P$ for trend & $<0.0001$ & & $<0.0001$ & \\
\hline \multicolumn{5}{|l|}{ Women } \\
\hline & \multicolumn{2}{|c|}{ Waist circumference $<90 \mathrm{~cm}$} & \multicolumn{2}{|c|}{ Waist circumference $\geq 90 \mathrm{~cm}$} \\
\hline 0 & 1.00 & Reference & 9.59 & $4.32-21.3$ \\
\hline 1 & 2.32 & $1.56-3.46$ & 7.37 & $3.80-14.3$ \\
\hline 2 & 5.42 & $3.10-9.48$ & 17.4 & $6.45-46.8$ \\
\hline 3 & 55.3 & $6.34-483$ & 44.2 & $4.85-403$ \\
\hline \multirow[t]{2}{*}{$P$ for trend } & $<0.0001$ & & $<0.0001$ & \\
\hline & \multicolumn{2}{|c|}{ Waist circumference $<80 \mathrm{~cm}$} & \multicolumn{2}{|c|}{ Waist circumference $\geq 80 \mathrm{~cm}$} \\
\hline 0 & 1.00 & Reference & 6.67 & $3.82-11.7$ \\
\hline 1 & 2.67 & $1.45-4.92$ & 8.63 & $5.04-14.8$ \\
\hline 2 & 6.02 & $2.70-13.4$ & 26.0 & $12.5-54.1$ \\
\hline 3 & 62.4 & $6.23-626$ & 125 & $14.4-1084$ \\
\hline$P$ for trend & \multicolumn{2}{|l|}{$<0.0001$} & \multicolumn{2}{|l|}{$<0.0001$} \\
\hline
\end{tabular}

${ }^{a}$ Number of the components of metabolic syndrome other than abdominal obesity 

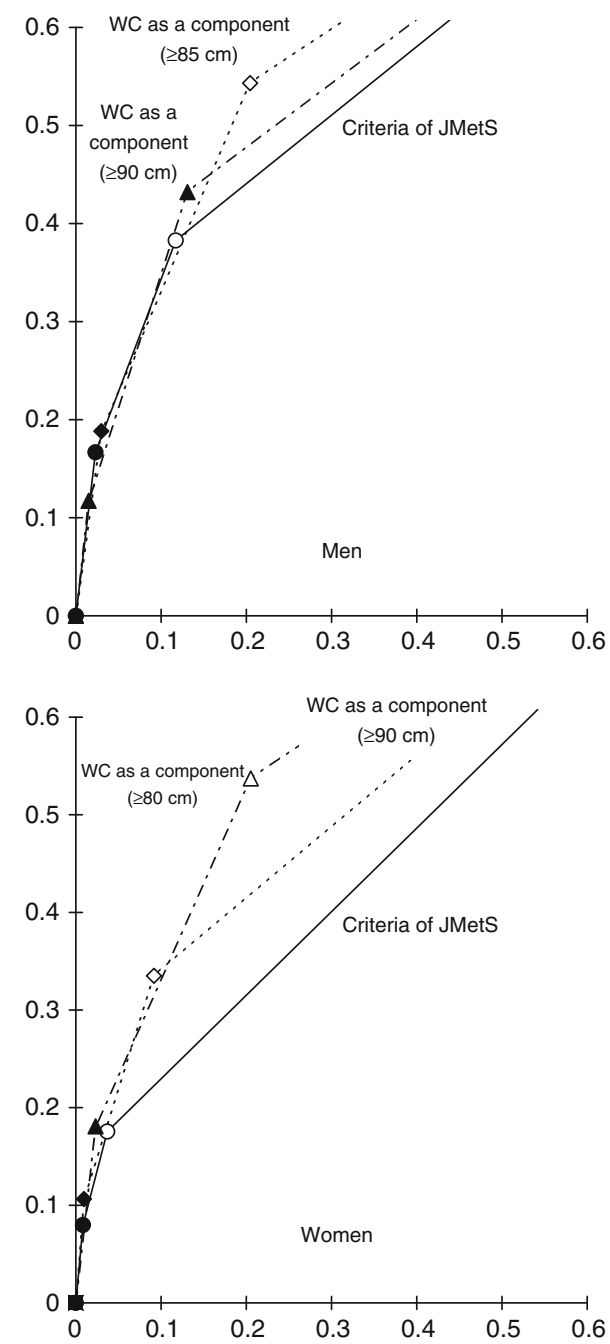

Fig. 1 Receiver operating characteristic curves for fatty liver diagnosis by metabolic syndrome status of several criteria. JMetS Japanese metabolic syndrom, $W C$ waist circumference

\section{Discussion}

In the present study, we considered concurrent fatty liver to be a specific example of a disease in the metabolic domino of MetS and observed that the accumulation of MetS components was associated with higher odds ratios, even without the central obesity component. Taking these results as a whole, we observed stronger associations between MetS and fatty liver in men and women when we considered central obesity as a component rather than an essential requirement for the diagnosis of MetS. We therefore suggest that individuals with an accumulation of components should be regarded as having MetS even in the absence of central obesity, since fatty liver is a component of the metabolic domino. In addition, these individuals may belong to a risk group for other metabolic diseases, including cardiac arrest and cerebrovascular diseases. We also suggest that the optimal COP for WC should be $\geq 85 \mathrm{~cm}$ for men and $\geq 80 \mathrm{~cm}$ for women.

Although the main concepts of MetS are consistent, the COPs for defining central obesity for MetS are controversial, especially in Japan [21]. Several studies have been performed to elucidate the optimal COPs in which ROC analyses with obesity and two or more MetS components other than obesity [22-25] were used. The results suggested that the optimal cut-offs for men and women are 8490 and 78-82 cm, respectively. Our results are consist with these reported values. However, these earlier studies were based on the internal consistency of obesity and MetS components other than obesity. Further ROC analyses need to be performed to establish the optimal COP for WC, and these should include certain diseases not currently included in MetS. This study is one such analysis.

An important question is whether central obesity should be considered as a requirement for the diagnosis of MetS or as a component of MetS. To answer this question, we need to examine the association between the number of MetS components and particular diseases stratified by central obesity. To date, there have been only two prospective cohort studies [26, 27] from Japan on cardiovascular diseases. Results from NIPPON DATA [26] show the existence of risk accumulation among non-obese subjects, whereas those from Hisayama-cho [27] indicate there is no risk accumulation in such subjects. Data from many studies, including those from our study, are required to facilitate further discussion on this question. However, before the absence of risk accumulation can be established among non-obese individuals, it is possible to treat central obesity as a component of MetS as a precautionary measure.

In general, if a factor is considered to be an essential requirement for the diagnosis of a certain disease, then that factor should not only be etiologically essential but also amenable to accurate measurement in practice; at the very least, the COP should be a sensitive measure. Otherwise, a considerable number of cases would not be detected by the criterion. In fact, the COPs based on the IDF criteria ( $\geq 94 \mathrm{~cm}$ for men and $\geq 80 \mathrm{~cm}$ for women), with central obesity as a requirement, are more sensitive than those of the NCEP-ATP III criteria $(\geq 102 \mathrm{~cm}$ for men and $\geq 88 \mathrm{~cm}$ for women), wherein central obesity is considered a component. Although the JMetS definition is similar to the IDF definition, the JMetS COP for WC in women $(\geq 90 \mathrm{~cm})$ is much less sensitive than the COP of the IDF $(\geq 80 \mathrm{~cm})$. The COP for central obesity for the diagnosis of JMetS is based on the association between visceral fat area and WC [16]. The committee reported that simple correlation analysis of the regression line in women indicated that a WC corresponding to $100 \mathrm{~cm}^{2}$ of visceral fat was $92.5 \mathrm{~cm}$. However, the correlation coefficient was only 0.65 , and more than half of the women with a visceral fat area 
$\geq 100 \mathrm{~cm}^{2}$ would not be found using the WC COP of $\geq 90 \mathrm{~cm}$ (meaning that sensitivity is $<0.5$ ). The poor sensitivity of the WC in detecting abdominal adiposity is directly linked to the poor sensitivity of the JMetS criteria, in which $\mathrm{WC}$ is an essential requirement.

\section{Conclusion}

Based on the findings of our study, we suggest that a WC of $\geq 85 \mathrm{~cm}$ for men and $\geq 80 \mathrm{~cm}$ for women would be optimal COPs for central obesity for the diagnosis of MetS in the Japanese population. We also suggest that central obesity should be used as a component of MetS rather than an essential requirement for the diagnosis of MetS. No definite conclusion has yet been reached regarding the most appropriate diagnostic criteria for MetS. However, within the framework of our study in which fatty liver was considered to be an independent variable, we found that defining abdominal circumference as a component of MetS was less likely to cause errors of oversight and was thus more appropriate than considering abdominal circumference to be a required criterion. The challenge for the future is to identify pathologic conditions that are responsible for MetS and to find better diagnostic criteria through further similar studies that consider factors, other than fatty liver, involved in the metabolic domino effect $[11,12]$ as independent variables.

Acknowledgments This study was supported in part by a Grantin-Aid for Scientific Research (C) (19590643) from the Ministry of Education, Culture, Sports, Science and Technology of Japan.

\section{References}

1. Matsuzawa Y. Definition and history of metabolic syndrome (in Japanese). Nippon Rinsho. 2006;64:9-12.

2. Wlodarczyk A, Strojek K. Glucose intolerance, insulin resistance and metabolic syndrome in patients with stable angina pectoris. Obesity predicts coronary atherosclerosis and dysglycemia. Pol Arch Med Wewn. 2008;118:719-26.

3. Bulugahapitiya U, Siyambalapitiya S, Sithole J, et al. The clinical impact of identifying metabolic syndrome in patients with diabetes: a cross-sectional study. Diab Vasc Dis Res. 2009;6:21-4.

4. Ford ES, Schulze MB, Pischon T, et al. Metabolic syndrome and risk of incident diabetes: findings from the European prospective investigation into cancer and nutrition-potsdam study. Cardiovasc Diabetol. 2008;7:35.

5. Wannamethee SG, Shaper AG, Lennon L, et al. Metabolic syndrome vs Framingham Risk Score for prediction of coronary heart disease, stroke, and type 2 diabetes mellitus. Arch Intern Med. 2005; 165:2644-50.

6. McNeill AM, Rosamond WD, Girman CJ, et al. The metabolic syndrome and 11-year risk of incident cardiovascular disease in the atherosclerosis risk in communities study. Diabetes Care. 2005;28:385-90.

7. Kanauchi M, Kanauchi K, Hashimoto T, et al. Metabolic syndrome and new category 'pre-hypertension' in a Japanese population. Curr Med Res Opin. 2004;20(9):1365-70.
8. Malik S, Wong ND, Franklin SS, et al. Impact of the metabolic syndrome on mortality from coronary heart disease, cardiovascular disease, and all causes in United States adults. Circulation. 2004; 110:1245-50.

9. Dart AM, Chin-Dusting JP. Lipids and the endothelium. Cardiovasc Res. 1999;43:308-22.

10. Lindsay RS, Wake DJ, Nair S, et al. Subcutaneous adipose 11 beta-hydroxysteroid dehydrogenase type 1 activity and messenger ribonucleic acid levels are associated with adiposity and insulinemia in Pima Indians and Caucasians. J Clin Endocrinol Metab. 2003;88:2738-44.

11. Itoh $\mathrm{H}$. What is 'metabolic domino effect'?-new concept in lifestyle-related disease (in Japanese). Nippon Rinsho. 2003; 61:1837-43.

12. Itoh H. Metabolic domino: new concept in lifestyle medicine. Drugs Today. 2006;42:9-16.

13. World Health Organization. Definition, diagnosis classification of diabetes mellitus, its complications. Part 1: Diagnosis and classification of diabetes mellitus. Geneva: World Health Organization; 1999.

14. Expert panel on detection, evaluation, treatment of high blood cholesterol in adults. Executive summary of the third report of national cholesterol education program (NCEP) expert panel on detection, evaluation, and treatment of high blood cholesterol in adults. JAMA. 2001;285:2486-97.

15. Alberti KG, Zimmet $P$, Shaw J. International diabetes federation: a consensus on Type 2 diabetes prevention. Diabetes Med. 2007;24:451-63.

16. The Examination Committee for Criteria of Metabolic Syndrome. Definition and criteria of metabolic syndrome (in Japanese). J Jpn Soc Intern Med. 2005;94:794-809.

17. Taylor KJ, Carpenter DA, Hill CR, et al. Gray scale ultrasound imaging. The anatomy and pathology of the liver. Radiology. 1976;119:415-23.

18. Joseph AE, Dewbury KC, McGuire PG. Ultrasound in the detection of chronic liver disease (the "bright liver"). $\mathrm{Br}$ J Radiol. 1979;52:184-8.

19. Kurtz AB, Dubbins PA, Rubin CS, et al. Echogenicity: analysis, significance, and masking. Am J Roentgenol. 1981;137:471-6.

20. Yajima Y, Ohta K, Narui T, et al. Ultrasound in the diagnosis of diffuse liver disease (in Japanese). Rinsho Hoshasen. 1982;27:553-7.

21. Oda E, Abe M, Veeraveedu PT, et al. Considerable disagreement among definitions of metabolic syndrome for Japanese. Circ J. 2007;71:1239-43.

22. Oka R, Kobayashi J, Yagi K, et al. Reassessment of the cutoff values of waist circumference and visceral fat area for identifying Japanese subjects at risk for the metabolic syndrome. Diabetes Res Clin Pract. 2008;79:474-81.

23. Baik I. Optimal cutoff points of waist circumference for the criteria of abdominal obesity: comparison with the criteria of the International Diabetes Federation. Circ J. 2009;73:2068-75.

24. Sato A, Asayama K, Ohkubo T, et al. Optimal cutoff point of waist circumference and use of home blood pressure as a definition of metabolic syndrome: the Ohasama study. Am J Hypertens. 2008;21:514-20.

25. Hara K, Matsushita Y, Horikoshi M, et al. A proposal for the cutoff point of waist circumference for the diagnosis of metabolic syndrome in the Japanese population. Diabetes Care. 2006;29:1123-4.

26. Kadota A, Hozawa A, Okamura $\mathrm{T}$, et al. NIPPON DATA Research Group. Relationship between metabolic risk factor clustering and cardiovascular mortality stratified by high blood glucose and obesity: NIPPON DATA90, 1990-2000. Diabetes Care. 2007;30:1533-8.

27. Doi Y, Ninomiya T, Hata J, et al. Proposed criteria for metabolic syndrome in Japanese based on prospective evidence: the Hisayama study. Stroke. 2009;40:1187-94. 